\title{
COMPARISON BETWEEN HI AND ELISA IN DETECTING IMMUNE TITER FOLLOWING IBV VACCINATION
}

BAYOUMIE, H.A.A. and HIKAL, M.A.G.

*Senior Researcher, Animal health Res. Inst. Zagazig (Poult .Dis. Dept.)

** Colleauge of Poult. And Rabbit Dis. (Vet. Hospital) Facult. Vet. Med. Zagazig Univ.

Email: heshambayoumie@yahoo.com

\section{ABSTRACT}

Received at: 5/11/2014

Accepted: 9/12/2014
Serological assays can be used for evaluating immune response post vaccination, they can be also helpful in studying the status of maternally derived antibodies (MDA), and they can also give a diagnostic mirror for viral sero-epidemiology. In the present study comparison between hemagglutination inhibition test (HI) and Enzyme linked immunesorbant assay (ELISA) and their abilities to detect IBV antibodies at different circumstances (post vaccination, infection, and (MDA) was studied. HI test for IBV was performed against two distinct IBV serotypes namely (Mass- 41, 4/91). Since they are the major vaccines used commercially in the Egyptian market. ELISA was performed at two dilutions (1/100, 1/ 1000) which is nearly the reciprocal of dilution of (7 and 10) in HI test in a trial to set two points for comparing the obtained results From the two tests. ELISA test showed 100\% sensitivity and specificity at dilution $1 / 100$ and showed 80.96\%, $95.5 \%$ respectively at $1 / 1000$ dilution. The sensitivity and specificity of $\mathrm{HI}$ test were $80.91 \%, 95 \%$ respectively when Mass-41 antigen was used and was $73.91 \%, 62$ $\%$ when $4 / 91$ antigen was used .The difference in sensitivity and specificity with $\mathrm{HI}$ reflects it selectivity during serotyping and this picture will necessarily differ if samples were tested against other antigens like (D- 274, 1466,.....etc.,) this confirms our point of view for using HI in detecting immunity after IBV vaccination. It became obvious that ELISA result may be misleading as seen during studying MDA in sample (S-20), ELISA reading at 1/100 dilution was $12051 \pm 2018$ with STDV(6384) and was $2406 \pm 754$ with $\operatorname{STDV}(2385)$ at dilution $1 / 1000$ their Conversion into two base $\log$ titer $1 / 10$ will be $14.28 \pm .317$ and $14.56 \pm .4$ respectively on the other hand the HI titer was $4.5 \pm .166$ with $\operatorname{STDV}(0.5)$

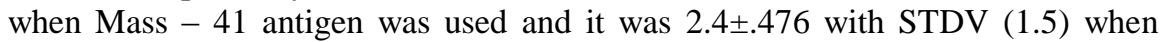
antigen 4/91 was used, result of ELISA will be conflicting when devising a vaccination protocol for such flock.

Keywords: IBV, HI, ELISA.

\section{INTRODUCTION}

Infectious Bronchitis Virus (IBV) is a highly contagious acute viral disease of the upper respiratory tract of chickens, it can also replicate in epithelial tissues of kidneys, gonads and oviduct of chickens causing their pathology and affecting the performance Lee et al. (2004).

IBV contains four structural proteins. The spike (S), and membrane (M) glycoproteins, a small membrane protein $(\mathrm{E})$, and the internal nucleo-capsid protein $(\mathrm{N})$ Spaan et al. (1988). The $\mathrm{S}$ protein is comprised of two subunits, S1, which forms the globular head of the spike protein, and S2, which anchors the S protein in the membrane. The S1 glycoprotein is known to induce the production of neutralizing and hemagglutination inhibition (HI) antibodies Ignjatovic and Galli (1995). The N protein is involved in cell-mediated immune responses while the $M$ protein of IBV is not recognized as an immunogenic protein Seo et al. (1997).

Prevention of IB is achieved mainly through vaccination. Although in most cases IBV strains within a geographic region are distinct as mentioned by Callison et al. (2001), Gelb et al. (2005), Ignjatovic et al. (2006). Because IBV undergoes frequent changes in the viral genome, mainly in the $\mathrm{S} 1$ gene which result in point mutations promoting the emergence of new antigenic variants Bochkov et al. (2007), Ammayappan et al. (2008) and Lee et al. (2008). The multiple IBV serotypes and its antigenic variation adds complexity to the proper selection of vaccination protocol and proper selection of serologic method to analyses the test results Jackwood and De Wit (2013). 
Vaccine strains should be selected to represent the antigenic spectrum of isolates in a particular region, because attenuated vaccines are known to have a limited range of protection, confined in many cases to homologous strains, rendering vaccination partially successful Lin et al. (2005). The use of heterologous vaccine strains, either simultaneouor sequentially, has broadened the protection spectrum in some cases Cook et al. (1999), but it is difficult to predict which combinations may confer the best protection. On the other hand, more virulent vaccine strains may have a broader range of protection, but their use is not recommended to avoid the risk of a disease outbreak Darbyshire (1985)
In the present study we were focusing on the value of $\mathrm{HI}$ test in detecting antibodies against IBV, since it can give an individual outlook for the immune titer for each vaccine used when distinct IB viral antigens are used, this enables corrective action whenever a problem is detected. On the contrary to ELISA which is giving one total outlook for IBV immune titer post vaccination.

\section{MATERIALS}

\section{1 -Serum samples}

Table (1) shows the vaccination history, source and number of the collected serum samples.

Table 1: Vaccination history of samples under investigation.

\begin{tabular}{|c|c|c|c|c|c|}
\hline \multirow{2}{*}{$\begin{array}{l}\text { Lab. Ref. } \\
\text { No. }\end{array}$} & \multirow{2}{*}{$\begin{array}{c}\text { No. of } \\
\text { samples }\end{array}$} & \multirow[t]{2}{*}{ Breed } & \multirow{2}{*}{$\begin{array}{l}\text { Age at } \\
\text { sample } \\
\text { collection }\end{array}$} & \multicolumn{2}{|r|}{ Vaccination history } \\
\hline & & & & Age In days & Vaccines \\
\hline$S-8$ & 10 & Bro. & $24 \mathrm{D}$ & $\begin{array}{ll}1 & D \\
9 & D \\
14 & D \\
\end{array}$ & $\begin{array}{l}\text { HB1+IBV (H120) } \\
\text { IBV - Ma } 5 \\
\text { IBV - 4/91 }\end{array}$ \\
\hline S - 14 & 22 & Lay. & $182 \mathrm{D}$ & $\begin{array}{cc}1 & D \\
9 & D \\
21 & D \\
35 & D \\
42 & D \\
63 & D \\
100 & D \\
110 & D \\
\end{array}$ & $\begin{array}{l}\text { IB Primer(H120+D-274) } \\
\text { IBV - 4/91 } \\
\text { IBV - Ma } 5 \\
\text { Triple inact.(NDV,EDS76r,IBV) } \\
\text { IBV - H } 120 \\
\text { IBV - Ma } 5 \\
\text { IBV- H120 } \\
\text { Triple inact.(NDV,EDS76,IBV) }\end{array}$ \\
\hline$S-15$ & 18 & Lay. & $280 \mathrm{D}$ & $\begin{array}{r}1 \mathrm{D} \\
8 \mathrm{D} \\
15 \mathrm{D} \\
40 \mathrm{D} \\
80 \mathrm{D} \\
102 \mathrm{D}\end{array}$ & $\begin{array}{l}\text { IBV - H120 } \\
\text { Triple inact.(NDV,EDS76,IBV) } \\
\text { IBV - 4/91 } \\
\text { IBV - Ma } 5 \\
\text { IBV - 4/91 } \\
\text { Triple inact.(NDV,EDS76,IBV) }\end{array}$ \\
\hline$S-16$ & 4 & Bro. & $32 \mathrm{D}$ & $\begin{array}{ll}1 & D \\
14 & D\end{array}$ & $\begin{array}{l}\text { IB Primer(H120+D-274) } \\
\text { IB Primer(H120+D-274) }\end{array}$ \\
\hline $\mathrm{S}-18$ & 4 & Bro. & $32 \mathrm{D}$ & No data & Randum \\
\hline$S-19$ & 10 & Lay. & $245 \mathrm{D}$ & $\begin{array}{r}6 \mathrm{D} \\
13 \mathrm{D} \\
\end{array}$ & $\begin{array}{l}\text { HB1+IBV(H 120) } \\
\text { Triple inact.(NDV,EDS76,IBV) }\end{array}$ \\
\hline$S-20$ & 10 & Bro. & $1 \mathrm{D}$ & --- & MDA \\
\hline$S-22$ & 6 & Lay. & $245 \mathrm{D}$ & $\begin{array}{r}1 \mathrm{D} \\
8 \mathrm{D} \\
15 \mathrm{D} \\
40 \mathrm{D} \\
80 \mathrm{D} \\
102 \mathrm{D} \\
\end{array}$ & $\begin{array}{l}\text { H120 } \\
\text { Triple inact.(NDV,EDS76,IBV) } \\
\text { IBV - 4/91 } \\
\text { IBV - Ma } 5 \\
\text { IBV - 4/91 } \\
\text { Triple inact.(NDV,EDS76,IBV) }\end{array}$ \\
\hline$S-23$ & 8 & Bro. & $24 \mathrm{D}$ & $\begin{array}{l}1 \mathrm{D} \\
7 \mathrm{D}\end{array}$ & $\begin{array}{l}\text { IB Primer(H120+D-274) } \\
\text { HB1+IBV }\end{array}$ \\
\hline Total & & & & 92 sampl & \\
\hline
\end{tabular}




\section{2 - Chicken RBCS}

Chicken RBCS were obtained from three 28 day old specific antibody negative chicken (SAN) raised for this purpose.

\section{3 - Saline}

Sodium chloride 0.9\% (ADWIC) ®, Sterile Pyrogen free.

\section{4 - ELISA kit.}

Commercial IBV ELISA kit (Proflock; Synbiotics Corporation). Lot.1202487

\section{5 - IB viral antigen}

IB viral antigens for HI test were obtained from GD Holland, \{(Mass- 41) lot 11531-010811 exp. 8/2021, (4/91) lot 09601-020209 exp.8/2019.

\section{6 - Negative serum}

Sera from day old SPF chicks were used.

\section{METHODS}

Haemagglutination inhibition test (HI).

HI tests, using IBV antigens (Mass-41 and 4/91) were performed as described by Villegas (1991), Villegas (2006). Serum dilutions ranged from 1:2 to 1:1024. All HI titers were expressed as Iog2 of the reciprocal of the highest serum dilution showing complete HI.

\section{ELISA test}

Serum samples were assayed in the commercial IBV ELISA systems $1: 100$ and $1: 1000$ dilutions, respectively, according to the manufacturer's instructions. Serum-to positive ratios (SP-ratios) were calculated, using the SP ratio formula:

From these SP-ratios, titers expressed as Iog2 values, were calculated using identical regression formulas (Synbiotics software) for both tests. Also used were the positive-negative SP cut-off values of 0.200 Synbiotics IBV ELISA according to the manufacturer recommendation.

$\frac{\text { OD sample - OD negative control }}{\text { OD positive control - OD negative control }}$

\section{Statistical analysis.}

Data were statistically analyzed as described by Snedecor and Cochran (1967). Using SPSS.16 computer program, value was used to determine significance.

\section{RESULT}

Results of the present work are illustrated in tables (27).

Table 2: The Geometric mean titer (GMT) of ELISA titer at dilution 1/100, and their conversion into two base logarithmic titer $1 / 10$

GMT of Elisa titer at dilution 1/100
Converting GMT of Elisa titer at dilution 1/100 multiplied *10

into two base log.titer 1/10 (Brugh 1978)

\begin{tabular}{|c|c|c|c|c|c|c|c|c|c|c|c|c|c|c|c|c|c|}
\hline \multicolumn{9}{|c|}{$A$ - Portion } & \multicolumn{9}{|c|}{ B-Portion } \\
\hline $\begin{array}{l}\infty \\
\dot{1}\end{array}$ & $\begin{array}{l} \pm \\
\text { is }\end{array}$ & $\begin{array}{l}n \\
\text { in }\end{array}$ & $\frac{a}{1}$ & $\stackrel{\infty}{\stackrel{\infty}{1}}$ & $\frac{9}{1}$ & $\begin{array}{l}\text { ì } \\
\text { is }\end{array}$ & $\begin{array}{l}\text { N } \\
\text { is }\end{array}$ & $\begin{array}{l}\dddot{y} \\
\dot{n}\end{array}$ & $\begin{array}{l}\infty \\
\text { is }\end{array}$ & $\begin{array}{l} \pm \\
\text { is }\end{array}$ & $\frac{n}{n}$ & $\begin{array}{l}\frac{1}{1} \\
\text { in }\end{array}$ & $\stackrel{\infty}{\stackrel{\infty}{1}}$ & $\begin{array}{l}\overrightarrow{1} \\
\text { is }\end{array}$ & $\begin{array}{l}\text { フे } \\
\text { is }\end{array}$ & $\begin{array}{l}\tilde{N} \\
\text { n }\end{array}$ & $\begin{array}{l}\ddot{y} \\
\dot{n}\end{array}$ \\
\hline 20356 & 5788 & 19443 & 5960 & 1355 & 15032 & 13455 & 9684 & 26322 & 15.3 & 13.5 & 15.2 & 13.5 & 11.4 & 14.8 & 14.7 & 14.2 & 15.7 \\
\hline 8642 & 16496 & 11677 & 10619 & 6865 & 17853 & 4213 & 3785 & 22288 & 14 & 15 & 14.5 & 14.3 & 13.7 & 15.1 & 13.1 & 12.8 & 15.4 \\
\hline 7497 & 17169 & 18039 & 5041 & 8722 & 19884 & 17483 & 8984 & 17853 & 13.8 & 15.1 & 15.1 & 13.4 & 14 & 15.2 & 15.1 & 14.2 & 15.1 \\
\hline 11099 & 13717 & 22869 & 1269 & 20861 & 22694 & 11275 & 4441 & 7648 & 14.4 & 14.7 & 15.4 & 11.4 & 15.3 & 15.4 & 14.5 & 16 & 13.9 \\
\hline 9746 & 22869 & 23132 & & & 16702 & 16857 & 4612 & 15681 & 14.2 & 15.4 & 15.5 & & & 15 & 15 & 13.1 & 14.9 \\
\hline 17747 & 20189 & 21455 & & & 23249 & 13861 & 6415 & 16137 & 15.1 & 15.3 & 15.4 & & & 15.5 & 14.7 & 13.6 & 14.9 \\
\hline 8286 & 22869 & 17481 & & & 13813 & 11727 & & 1688 & 14 & 15.4 & 15.1 & & & 14.7 & 14.5 & & 11.7 \\
\hline 76686 & 22345 & 22201 & & & 7478 & 2330 & & 9935 & 15.9 & 15.4 & 15.5 & & & 13.8 & 12.2 & & 10.9 \\
\hline 10147 & 20664 & 14126 & & & 3901 & 6327 & & & 14.3 & 15.3 & 14.7 & & & 12.9 & 13.6 & & \\
\hline 3974 & 20078 & 17169 & & & 8783 & 22985 & & & 12.9 & 15.2 & 15 & & & 14.1 & 15.4 & & \\
\hline & 21427 & 21798 & & & & & & & & 15.3 & 15.4 & & & & & & \\
\hline & 21002 & 22172 & & & & & & & & 15.3 & 15.4 & & & & & & \\
\hline & 16086 & 20468 & & & & & & & & 14.9 & 15.3 & & & & & & \\
\hline & 21569 & 21970 & & & & & & & & 15.4 & 15.4 & & & & & & \\
\hline & 19279 & 22259 & & & & & & & & 15.2 & 15.4 & & & & & & \\
\hline & 20636 & 17510 & & & & & & & & 15.3 & 15.1 & & & & & & \\
\hline & 23220 & 16444 & & & & & & & & 15.5 & 15 & & & & & & \\
\hline & 21256 & 17143 & & & & & & & & 15.3 & 15 & & & & & & \\
\hline & 14077 & & & & & & & & & 15.3 & & & & & & & \\
\hline & 21856 & & & & & & & & & 14.7 & & & & & & & \\
\hline & 20973 & & & & & & & & & 15.4 & & & & & & & \\
\hline & 21455 & & & & & & & & & 15.3 & & & & & & & \\
\hline 10 & 22 & 18 & 4 & 4 & 10 & 10 & 6 & 8 & 10 & 22 & 18 & 4 & 4 & 10 & 10 & 6 & 8 \\
\hline
\end{tabular}


Table 3: The Geometric mean titer (GMT) of ELISA titer at dilution 1/1000, and their conversion into two base logarithmic titer $1 / 10$.

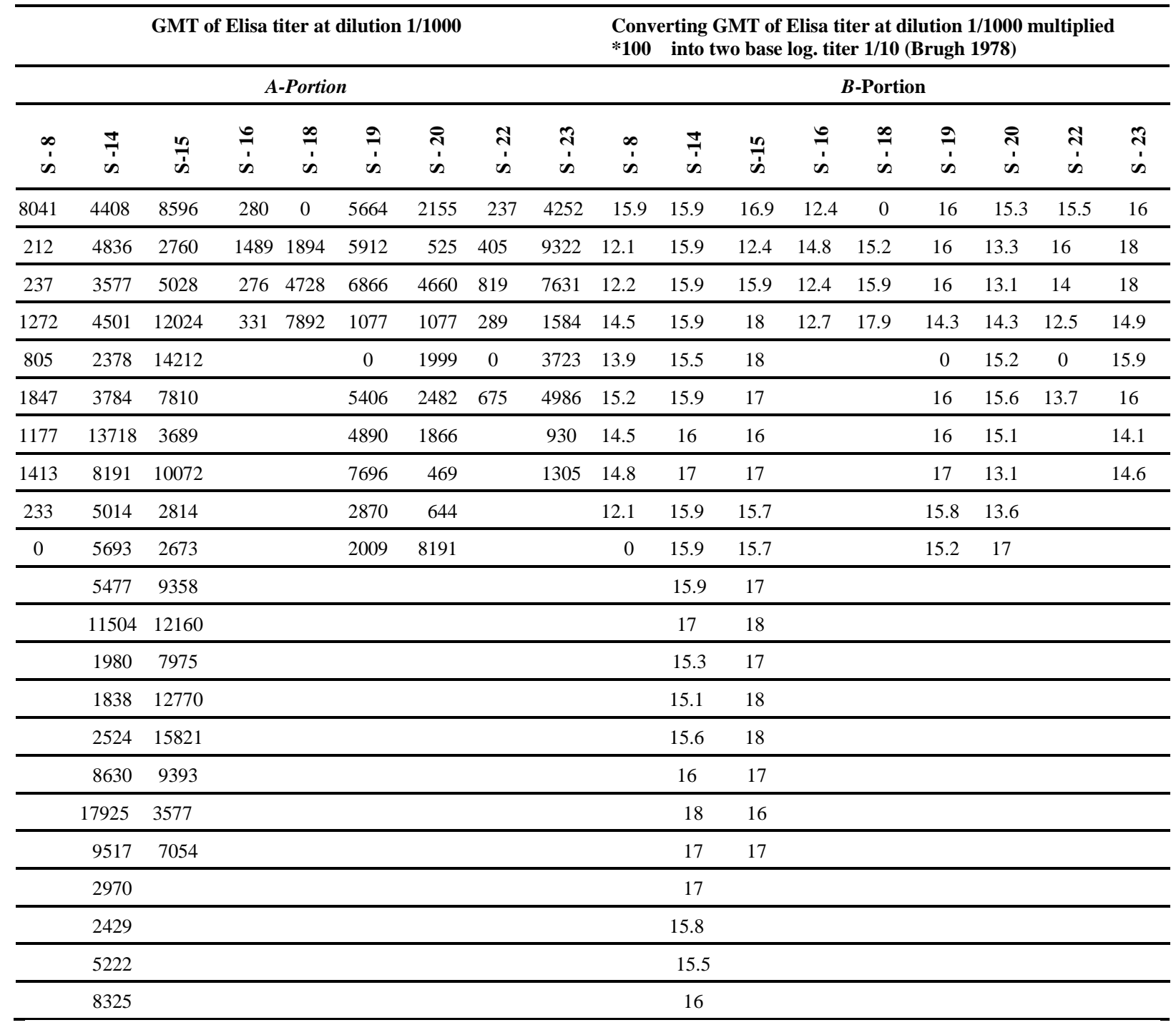

Table 4: Haemagglutination inhibition (HI) titer of examined samples using Mass-41 and 4/91 IBV antigens

\begin{tabular}{|c|c|c|c|c|c|c|c|c|c|c|c|c|c|c|c|c|c|c|c|c|}
\hline \multirow{3}{*}{ 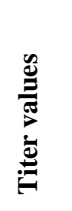 } & \multicolumn{10}{|c|}{ HI Mass-41 } & \multicolumn{10}{|c|}{ HI- 4/91 } \\
\hline & $\begin{array}{l}\infty \\
1 \\
n\end{array}$ & $\frac{\Delta}{1}$ & $\frac{n}{n}$ & $\begin{array}{l}0 \\
\text { is }\end{array}$ & $\frac{\infty}{1}$ & $\frac{a}{1}$ & $\begin{array}{l}\text { ते } \\
\text { is }\end{array}$ & $\begin{array}{l}\tilde{N} \\
\dot{1} \\
\dot{n}\end{array}$ & $\begin{array}{l}\hat{7} \\
\dot{1}\end{array}$ & \multirow{2}{*}{ ฮึ } & $\begin{array}{l}\infty \\
1 \\
\text { is }\end{array}$ & $\frac{\pi}{7}$ & $\frac{n}{n}$ & $\begin{array}{l}0 \\
\text { is }\end{array}$ & $\begin{array}{l}\infty \\
\dot{1} \\
\text { is }\end{array}$ & $\begin{array}{l}\overrightarrow{1} \\
\text { is }\end{array}$ & $\begin{array}{l}\text { iे } \\
\text { is }\end{array}$ & $\begin{array}{l}\tilde{3} \\
\text { n' }\end{array}$ & $\begin{array}{l}\tilde{i} \\
\dot{n} \\
\text { s. }\end{array}$ & ฮٓ \\
\hline & \multicolumn{9}{|c|}{ Number of values } & & \multicolumn{10}{|c|}{ Number of values } \\
\hline 0 & & & & 1 & & & & & 3 & 4 & & & & 4 & 1 & 10 & 1 & & 8 & 24 \\
\hline 1 & & & & & & & & & 5 & 5 & & & & & 1 & & 2 & & & 3 \\
\hline 2 & 1 & & & & 1 & 2 & & & & 4 & 5 & & & & 1 & & 2 & & & 8 \\
\hline 3 & 2 & & & & 2 & 2 & & & & 6 & & & & & 1 & & 3 & & & 4 \\
\hline 4 & 1 & 5 & & & 1 & 2 & 5 & & & 14 & 5 & 4 & & & & & 1 & 3 & & 13 \\
\hline 5 & 3 & 8 & & 1 & & 3 & 5 & & & 20 & & 8 & & & & & 1 & 3 & & 12 \\
\hline 6 & 2 & 5 & 1 & & & 1 & & & & 9 & & 6 & 9 & & & & & & & 15 \\
\hline 7 & 1 & 2 & 5 & 2 & & & & & & 10 & & 3 & & & & & & & & 3 \\
\hline 8 & & 2 & 12 & & & & & & & 14 & & 1 & 9 & & & & & & & 10 \\
\hline \multicolumn{21}{|l|}{9} \\
\hline 10 & & & & & & & & 6 & & 6 & & & & & & & & & & \\
\hline total & 10 & 22 & 18 & 4 & 4 & 10 & 10 & 6 & 8 & & 10 & 22 & 18 & 4 & 4 & 10 & 10 & 6 & 8 & \\
\hline
\end{tabular}




\section{Assiut Vet. Med. J. Vol. 61 No. 144 January 2015}

Table 5: The Geometric mean titer (GMT) of ELISA titer at dilution 1/100, 1/1000 and their conversion into two base logarithmic titer $1 / 10$

\begin{tabular}{|c|c|c|c|c|c|c|c|c|c|}
\hline & $S-8$ & S -14 & S -15 & $S-16$ & S - 18 & S - 19 & $S-20$ & S - 22 & $S-23$ \\
\hline $\mathbf{A}$ & $17418 \pm 6759$ & $19319 \pm 869$ & $19279 \pm 772$ & $5722 \pm 1922$ & $9450 \pm 4112$ & $14938 \pm 2060$ & $12051 \pm 2018$ & $6320 \pm 1021$ & $14694 \pm 2826$ \\
\hline STDV & 21376.7 & 4078.2 & 3277.1 & 3844.05 & 8225 & 6514.3 & 6384 & 2501.8 & 7994.3 \\
\hline B & $14.39 \pm .2$ & $15.14 \pm .09$ & $15.1 \pm .06$ & $13.15 \pm .6$ & $13.6 \pm .8$ & $14.65 \pm .25$ & $14.28 \pm .317$ & $13.9 \pm .465$ & $14.1 \pm .6$ \\
\hline STDV & .851 & .427 & .278 & 1.23 & 1.6 & .81 & 1.004 & 1.139 & 1.7 \\
\hline $\mathbf{C}$ & $1523.7 \pm 750 *$ & $6110 \pm 883$ & $8210 \pm 980$ & $594 \pm 298 *$ & $3628.5 \pm 1721$ & $4239 \pm 818$ & $2406 \pm 754$ & $404 \pm 122$ & $4216 \pm 1075^{* *}$ \\
\hline STDV & 2372.4 & 4144.8 & 4160.6 & 597.1 & 3442.9 & 2588 & 2385 & 299.9 & 3041.8 \\
\hline D & $12.52 \pm 1.45$ & $16.09 \pm .14$ & $16.7 \pm .319$ & $13.07 \pm .57$ & $12.25 \pm 4.1$ & $14.23 \pm 1.59$ & $14.56 \pm .4$ & $11.9 \pm 2.44$ & $15.9 \pm .51 *$ \\
\hline STDV & 4.6 & .686 & 1.36 & 1.15 & 8.2 & 5.04 & 1.29 & 5.98 & 1.45 \\
\hline $\mathbf{E}$ & $4.7 \pm .5$ & $5.45 \pm .26$ & $7.61 \pm$ & $4.75 \pm 1.6$ & $3 \pm .405$ & $3.9 \pm .433$ & $4.5 \pm .166$ & 10 & $0.63 \pm .18$ \\
\hline STDV & 1.766 & 1.22 & 0.6 & 3.3 & 0.81 & 1.37 & 0.5 & 0 & 0.517 \\
\hline $\mathbf{F}$ & $3 \pm .33$ & $5.5 \pm .23$ & $7 \pm 1.02$ & 0 & $1.5 \pm .64$ & 0 & $2.4 \pm .476$ & $4.5 \pm .22$ & 0 \\
\hline STDV & 1.05 & 1.1 & 1.02 & 0 & 1.29 & 0 & 1.5 & 0.54 & 0 \\
\hline
\end{tabular}

$A=$ GMT of Elisa titer at dilution $1 / 100 *=0.05 \quad * *=0.01$.

$B=$ Converting GMT of Elisa titer at dilution 1/100 into two base logarithmic titer 1/10 (Brugh 1978).

$C=$ GMT of Elisa titer at dilution $1 / 1000 \quad S T D V .=$ standard deviation

$D=$ Converting GMT of Elisa titer at dilution 1/1000 into two base logarithmic titer 1/10 (Brugh 1978).

$E=$ Mean HI-Mass 41 .

$F=$ Mean $H I-4 / 91$

Table 6: Shows the sensitivity $\%$ and specificity $\%$ of applied serological tests.

\begin{tabular}{ccccc}
\hline & $\begin{array}{c}\text { ELISA at } \\
\text { dilution 1/100 }\end{array}$ & $\begin{array}{c}\text { ELISA at dilution } \\
\mathbf{1 / 1 0 0 0}\end{array}$ & HI using mass-41 & HI using 4/91 \\
\hline$*$ Sensitivity \% & $100 \%$ & $80.96 \%$ & $80.91 \%$ & $73.91 \%$ \\
\hline$*$ Specificity \% & $100 \%$ & $95.5 \%$ & $85 \%$ & $62 \%$ \\
\hline
\end{tabular}

$*$ Sensitivity $=\%$ of positives $/$ tested samples. $\quad * *$ specificity $=\%$ of negatives $/$ tested samples

Table 7: Shows the correlation between number and varieties of given vaccines, beside intervals up till sample collection and the recorded serological values with different serological tests.

\begin{tabular}{|c|c|c|c|c|c|c|c|c|c|c|}
\hline & \multicolumn{6}{|c|}{$\begin{array}{l}\text { Number and varieties of vaccinal strains given for } \\
\text { examined flocks }\end{array}$} & \multirow{3}{*}{$\begin{array}{c}\text { Time } \\
\text { elapsed } \\
\text { from } \\
\text { vaccination } \\
\text { till } \\
\text { sampling }\end{array}$} & \multirow{2}{*}{\multicolumn{2}{|c|}{ HI titers }} & \multirow{2}{*}{$\begin{array}{c}\text { ELISA } \\
\text { two base } \\
\text { log.titer } \\
1 / 10\end{array}$} \\
\hline & \multicolumn{3}{|c|}{$\begin{array}{c}\text { Classical vaccinal } \\
\text { strains }\end{array}$} & \multirow[t]{2}{*}{$\begin{array}{c}\text { Triple } \\
\text { inactivated } \\
\text { vaccine }\end{array}$} & \multicolumn{2}{|c|}{$\begin{array}{c}\text { Variant } \\
\text { vaccinal } \\
\text { strains } \\
\end{array}$} & & & & \\
\hline & $\begin{array}{c}\mathbf{H} \\
120\end{array}$ & Ma 5 & Mass-41 & & $4 / 91$ & $\begin{array}{c}\text { D } \\
274\end{array}$ & & $\begin{array}{c}\text { Mass- } \\
41\end{array}$ & $4 / 91$ & $\begin{array}{c}1 / 100 \\
\text { dilution }\end{array}$ \\
\hline$S-8$ & I & I & - & - & $\mathbf{I}$ & - & 10 days & 4.7 & 3 & 14.39 \\
\hline S -14 & III & II & - & II & $I$ & $I$ & 72 days & 5.45 & 5.5 & 15.14 \\
\hline $\begin{array}{l}\mathrm{S}- \\
15\end{array}$ & I & $I$ & - & II & II & - & 178 days & 7.61 & 7 & 15.1 \\
\hline $\begin{array}{l}S- \\
16\end{array}$ & II & - & - & - & - & II & 17 day & 4.75 & $\mathbf{0}$ & 13.15 \\
\hline $\begin{array}{l}S- \\
18\end{array}$ & & & & Random & & & & 3 & 1.5 & 13.6 \\
\hline $\begin{array}{l}S- \\
19\end{array}$ & I & - & - & I & - & - & 232 days & 3.9 & $\mathbf{0}$ & 14.65 \\
\hline $\begin{array}{l}\text { S - } \\
20\end{array}$ & & & & MDA & & & & 4.5 & 2.4 & 14.28 \\
\hline S -22 & $I$ & $I$ & - & II & II & - & 143 day & 10 & 4.5 & 13.9 \\
\hline $\begin{array}{l}S- \\
23\end{array}$ & II & - & - & - & - & - & 17 day & 0.63 & $\mathbf{0}$ & 14.1 \\
\hline
\end{tabular}




\section{DISCUSSION}

Prevention of IB relies mainly on vaccination, however it does not confer full protection against the heterologous IB variant strains. To devise a successful vaccination protocol against IBV it is necessary to isolate the circulating viruses in the locality and study their relatedness and cross protection Callison et al. (2001). The various viral strains of IB can be classified according to serotype, genotype and protectotype. using virus neutralization, or by genotyping, using RT PCR together with sequencing or a second specific-primer PCR, or, more rarely, using restriction fragment length polymorphism (RFLP) Worthington et al. (2008), this may not be feasible in developing countries and it is time consuming. Other workers such as Cook et al. (1999) though of combing classical and variant vaccines to widen the protection against IBV but this was not completely successful due to the large number of IBV serotypes and the lack of complete cross protection.

We thought that it might be helpful to use HI for the evaluation of the immune titer for two most prevalent vaccine strains in the Egyptian market, since this test is efficient in serotyping which will helpful in studying sero-conversion post vaccination with these strains, this procedure will allow a corrective procedure when vaccinal failure is detected, and we also suggested rules for interpretation of the $\mathrm{HI}$ and ELISA results.

The multiple IBV serotypes and its antigenic variation, adds complexity to the selection of an appropriate serologic method and to the analysis of test results. All IBV serotypes would seem to have common epitopes (group-specific antigens), which is given the moderately high amino acid sequence identity within the $\mathrm{N}$ and $\mathrm{M}$ proteins and the $\mathrm{S} 2$ part of the spike protein. IBVs also induce type-specific antibodies, determined by epitopes of the S1 protein Cavanagh and Gelb (2008). Jackwood and De Wit (2013).

The advantage of serological studies based on tests such as (HI and ELISA) is the historical aspect that they bring to the clinical case, since their results can measures the reaction of the bird to the disease causing agent over a period of time, whereas direct diagnostics such as (PCR) requires the presence of the virus at the very moment of sampling Auvigne et al. (2013).

ELISA testing is unable to differentiate the different infectious bronchitis serotypes, as this method involves antibody binding to group-specific as well as type- specific antigens Mockett and Darbyshire (1981). Macnaughton et al. (1981). The antibody response assessed by $\mathrm{HI}$ and $\mathrm{VN}$, may be used as an aid to the diagnosis of the predominant serotype present. Dhinakar and Jones (1997), Mockett and Darbyshire (1981).

In poultry, high specificity of serological tests is more important than high sensitivity, since low sensitivity can be compensated for, by using a higher number of blood samples. The sensitivity could be calculated as the percentages of positives while the specificity could be calculated as the percentage of negatives in the tested samples De Wit et al. (1997), De Wit (2000), Auvigne et al. (2013). In the present study the sensitivity of ELISA at dilution 1/ 100 was $100 \%$, and this percent was $80.96 \%$ when the dilution was $1 /$ 1000 , comparatively the HI test performed using Mass-41 antigen at cut off value 2 revealed that 80.92 $\%$ of the examined samples were positive for IBV antibodies and this percent was $73.91 \%$ when the 4/ 91 IBV antigen was used. The cut off value in the present study was set as $2^{2}$ (table -4 ) on the contrary for the previous work of Alexander and Chettle (1977), De wit et al. (1997) because Villegas (1991), Villegas (2006) were using 8 HA units, while Alexander and Chettle (1977), De wit et al. (1997) used 4 HA units of IBV antigen for the test, as for the specificity in the present study the percent of negative reactors in the examined samples using ELISA were (0/92) at dilution $1 / 100$ and was (4/92) i.e. $4.3 \%$ when ELISA was performed at dilution $1 / 1000$, and when HI was performed it was (14/92) i.e. $15.2 \%$ using Mass-41 antigen, and (35/92) i.e. $38 \%$ with 4/91 antigen. De wit et al. (1997) found that ELISA is moderately sensitive but highly specific when examining sera from non-vaccinated birds , and it is sensitive with variable specificity when examined sera were from vaccinated birds., as for HI test the results will depend on the cut off values and they recorded a specificity of $55-100 \%$ and wide variation in sensitivity. These result fortifies our findings, the wide variation in sensitivity is result of using distinct antigen i.e. (4/91 or Mass-41).

ELISA showed $100 \%$ sensitivity and specificity at dilution $1 / 100$ and showed $80.96 \%$, $95.5 \%$ respectively at $1 / 1000$ dilution. The sensitivity and specificity of $\mathrm{HI}$ were $80.91 \%$, $95 \%$ respectively when Mass-41 antigen was used and was $73.91 \%, 62$ $\%$ when 4/91 antigen was used. The difference in sensitivity and specificity with $\mathrm{HI}$ reflects it selectivity during serotyping and this picture will necessarily differ if samples were tested against other antigens like (D- 274, 1466,.....etc.,) this confirms our point of view for using $\mathrm{HI}$ in detecting immunity after IBV vaccination.

It became obvious that ELISA result may be misleading as seen during studying MDA in sample (S-20), ELISA reading at $1 / 100$ dilution was $12051 \pm 2018$ with STDV (6384) and was $2406 \pm 754$ with $\operatorname{STDV}(2385)$ at dilution $1 / 1000$ their Conversion 
into two base $\log$ titer $1 / 10$ will be $14.28 \pm .317$ and $14.56 \pm .4$ respectively on the other hand the HI titer was $4.5 \pm .166$ with $\operatorname{STDV}(0.5)$ when Mass - 41 antigen was used and it was $2.4 \pm .476$ with STDV (1.5) when antigen 4/91 was used, result of ELISA will be conflicting when devising a vaccination protocol for such flock.

The rational for ELISA at dilution 1/1000 is the high immune titers observed when dilution was $1 / 100$, and because that 4 out of 92 examined sample were negative (table -3 ) although 1:1000 in ELISA is very near for $1: 1024\left(10^{\text {th }}\right.$ dilution of HI starting $\left.1: 2\right)$ at which 6 samples out of 92 were only positive and the remaining 84 samples ended before the $9^{\text {th }}$ dilution, this had led us to carry on ELISA at dilution 1: 100 which is very near for $1: 128\left(7^{\text {th }}\right.$ dilution of $\mathrm{HI}$ starting 1:2) all examined samples were positive for ELISA and HI using Mass-41 IBV antigen but a different picture was observed when HI using 4/91 IBV antigen this confirms the hypothesis that with HI you can observe a distinctive pictures for each vaccinal strain used although examined samples were (100\%) positive for ELISA and HI using Mass-41 IBV antigen at dilution 1:100 and were (13/93) i.e. $14.13 \%$ when HI was performed using 4/91 antigen, and this confirms our point.

The ELISA technique is a sensitive serological method gives earlier reactions and higher antibody titers than other tests Mockett and Darbyshire (1981). Commercial ELISA kits used for monitoring serum antibody responses against IBV are broadly crossreactive among serotypes and allow for general serological monitoring of vaccinal responses and field challenges but it lacks strain specificity Karaca and Naqi. (1993), De Wit et al. (1997) commercially available. ELISAs detects IBV antibodies within one week of infection, earlier than by $\mathrm{HI}$ or VN tests Marquardt et al. (1981), Mockett and Darbyshire (1981), De Wit et al. (1997), De Wit (2000).

HI should be used for identifying serotype-specific responses to vaccination and field challenges in young growing chickens. Because with multiple infections and vaccinations, the sera of breeders and layers will be cross-reactive thus its results cannot be used with a high degree of confidence De Wit et al. (1998)., but the low cost, simple test equipment and speed of the HI test makes it a very useful procedure for routine diagnosis; the limitations must simply be borne in mind, and alternative analytical techniques should be at hand when doubt arises De Wit et al. (1997).

Standard protocol for HI for IBV has been described Villegas (1991), Villegas (2006) with minor changes from the protocol of Alexander and chettle (1977), the test procedure is based on that standard strains and isolates of IBV will agglutinate chicken red blood cells RBCs after neuraminidase treatment Ruano et al. (2000), Schultze et al. (1992). The strain selected to produce antigen may be varied, depending on the requirements of diagnosis. In the present study sera were analyzed by HI for two serotypes (Mass41and 4/91). The serum samples underwent serial halving dilution and were mixed with an equivalent amount of antigen. After incubation (30 min at $20^{\circ} \mathrm{C}$ ), washed chicken red blood cells (WCRBCS) from SAN chickens, prepared with an anticoagulant, were added. After incubation $(40 \mathrm{mn}$ at $20^{\circ} \mathrm{C}$ ), the results were read by inclination of the plaques and observation of the HI. The antibody titer of the serum sample, expressed in $\log 2$, corresponds to the highest serum dilution leading to complete inhibition. The highest tested titer is 10 , the well 11 was left for virus control and well 12 was left for (WCRBCS) control. The validity of results was ascertained by using a negative serum control sample that should not have a titer above or equal to $2 \log 2$.

Haemagglutinating antigen for the HI test could be prepared from chorioallantoic fluid harvested from IBV-inoculated embryonated chicken eggs. Neuraminidase type V in PBS (pH7.2 at 1, 0 units/ml final concentration is used to treat IBV for $30 \mathrm{~min}$ at 37 C) Ruano et al. (2000). Antigen titration is performed in standard U-bottom 96-well microtiter plates using (WCRBCS) close range of an initial series of dilutions, i.e. $1 / 3,1 / 4,1 / 5,1 / 6$, etc. gives more accurate initial titration. Treatment of IBV with bacterial phospholipase $\mathrm{C}$ was initially thought to enable the virus to agglutinate (WCRBCS) Alexander and Chettle (1977), King and Hopkins (1984). However, HA antigens produced using highly purified phospholipase $\mathrm{C}$ preparations often had considerably lower titers than those produced using unpurified phospholipase C preparations. Subsequent studies Ruano et al. (2000). Shultze et al. (1992) determined that treatment of IBV with purified neuraminidase preparations consistently produced high-titer HA antigens. These findings suggested that the unpurified phospholipase $\mathrm{C}$ preparations were contaminated with neuraminidase, this comparison will be the subject of our investigation during the intended antigen preparation trials.

Auvigne et al. (2013) used typology of the flock profiles using clustering methods. This allows grouping the flocks according to their resemblance without posing any prior hypothesis other than those used for the general study design (choice of flocks, age at sampling, sampling and testing). As a first step, a principal components analysis (PCA) was carried out to allow studying the overall variability of the dataset and creating new uncorrelated variables, summarizing information that may have a biological sense and that may contribute to differentiate groups. The study of the variability percentage explained by each of this new variables and their biological 
signification allow determining which of these new variables have to be retained for the rest of the analysis. As a second step, ascending Hierarchical Clustering (HC) was performed. For calculation of distances between individuals and then assembling them in groups according to proximity. The variables used in the $\mathrm{HC}$ to calculate the distances are the coordinates of the flocks on the retained axes by the PCA. The HC leads to a dendrogram used to define the optimal cluster number. This choice depends on the clearness of the separation between the dendrogram branches and on the number of flocks in each group. As a third step, the means of the new variables created at the PCA step are calculated for each of the groups and, using the k-means method, each flock is reassigned to the group with the nearest mean. The representation of these groups on the PCA axes allows determining the discriminatory axes between groups. If certain axes turn out to be nondiscriminatory, a new iteration of the analysis is performed. Finally, as a fourth step, the distribution characteristics of the 6 mean serological titers within each group are described and the biological meaning of these groups is investigated. Auvigne et al. (2013) mentioned the typological analysis allows interpretation of the results in spite of the existence of cross reactions. However, this method requires certain choices (number of axes, number of clusters) that have an impact on the final result, and it is not an absolute classification. However, the fact that the obtained classification is coherent with the data of experimental infections, even though the bibliographical data were not used for the classification, is in favor of its relevance. In the present study we were not able to use hierarchical clustering because setting a cut off values will not allow to consider values below this cut off .In the present study we used the EXCEL sheets to calculate what is presented in (table -5).

ELISA titers as seen in (table 2,3) couldn't be evaluated as it is, and It was also noticed the standard error of the values was very high ranging from (4 to $43 \%$ ) which is a very high values indicative of nonhomogeneous titers Kurian et al. (2012) examined heat treatment, repetitive freezing and thawing and three levels of severity of hemolysis as a sample mishandling treatments simulated different conditions that might occur during routine blood collection, transport or storage in a clinical practice setting. Each mishandling treatment was experimentally applied under laboratory conditions and then samples were assayed for antibodies against IBV, AEV and CAV using commercial ELISA kits. And found that severe hemolysis had the most consistent detrimental effect on ELISA performance, producing results that were significantly different from the reference standard in all three ELISAs, although the direction of the effect varied (less positive for the IBV and CAV assays; more positive for the AEV assay). Moderate levels of hemolysis had a similar, but less consistent, effect to that of severe hemolysis, producing results that were significantly different from the reference standard only for the IBV (less positive) and AEV (more positive) ELISAs. Repetitive freeze-thawing also produced a significant effect on ELISA results for IBV (less positive) and AEV (more positive). The IBV ELISA appeared to be most susceptible to the effects of serum maltreatment. The findings from this study suggest that unpredictable variation in the results of ELISAs can occur due to different sample mishandling treatments.

In the present study we converted the obtained ELISA results at dilution $1 / 100$ in (table-2) and that at dilution 1/1000 (table -3) into its two base logarithmic titer 1/10 (Brugh 1978), to obtain a numerical values that well facilitate the comparison between the two tests as performed by De Wit et al. (1997) After converting the GMT of ELISA titer $1 / 100$ multiplied by10 into its base $\log$ titer $1 / 10$ (Brugh 1978), you can observe that the figure 15.4 will represent the ELISA reading of (20973-22869) (table -2), this numeric values were very high compared to that of $\mathrm{HI}$ at dilution 7 or 10 which were zero in most examined samples.

In the present study serum samples submitted for investigation were collected from different flocks receiving different vaccination programs (table 1 ), the time interval from the last vaccine used until sample collection ranged from 10 to 232 day post vaccinations (Table-6), the mean two base log titer of ELISA at dilution 1/100 was ranging from (13.16 15.14) despite of the number of vaccine administration which ranged from ( 2 up to 9 times including inactivated vaccine) (table -6). It is also apparent that this high titers was observed in samples ( $\mathrm{S}-16,19$ and 23) these samples were from flocks that did not receive any variant vaccines, this apparent high titer masks the fact that birds are at risk if challenged with a variant. Comparatively HI titers observed were zero in sample (S- 16, 19 and 23) since their flock did not receive any vaccine of such strains so, although ELISA gave a sensitivity percent of $100 \%, 80.96 \%$ at the examined dilution (1/100, $1 / 1000)$ respectively and it also gave a specificity $(100 \%, 95.5)$ at the same dilutions, but this is not logic for the obtained results compared to HI results.

\section{REFERANSES}

Alexander, DJ. And Chettle, N.J. (1977): Procedures for HA and HI for avian IBV. Avian Pathl. 6: 9-17.

Ammayappan, A.; Upadhyay, C.; Gelb, J Jr. and Vakharia, VN. (2008): Complete genomic sequence analysis of IBV Ark DPI strain and its evolution by recombination. Virol J. 5: 157. 
Auvigne, V.; Gibaud, S.; Leger, L.; Malher, X.; Currie, R. and Riggi, A. (2013): A longitudinal study of incidence of IBV in France using strain-specific HI \& cluster analysis. Revue Méd. Vét, 164: 417- 424.

Bochkov, YA.; Tosi, G.; Massi, P. and Drygin, VV. (2007): Phylogenetic analysis of partial S1 and $\mathrm{N}$ gene of IBV isolates from Italy revealed genetic diversity and recombination. Virus Genes. 35: 65-71.

Brugh, MA. Jr. (1978): A simple method for recording and analyzing serological data. Avian Dis.22: 362- 365.

Callison, SA.; Jackwood, MW. and Hilt, DA. (2001): Molecular characterization of IBV isolates foreign to the United States and comparison with USA isolates. Avian Dis. 45: 492-499.

Cavanagh, D. and Gelb, J. (2008): IBV. In diseases of poultry $12^{\text {th }}$ ed. Editor Saif. Y.M.pp. 117-135.

Cook, JKA.; Orbell, SJ.; Woods, MA. and Huggins, MB. (1999): Breadth of protection of the respiratory tract provided by different liveattenuated infectious bronchitis vaccines against challenge with infectious bronchitis viruses of heterologous serotypes. Avian Pathol. 28: 477-485.

Darbyshire, JH. (1985): A clearance test to assess protection in chickens vaccinated against avian IBV. Avian Pathol. 14: 497-508.

De Wit, JJ. (2000): Detection of infectious bronchitis. Avian Pathology 29: 71, 93.

De Wit, JJ.; Mekkes, DR.; Kouwenhoven, B. and Verheijden, JH M. (1997): Sensitivity and specificity of serological tests for detection of IBV induced antibodies in broilers. Avian Pathol 26: 105-118.

De Wit, JJ.; Mekkes, DR.; Koch, G. and Westenbrink, $F$. (1998): Detection of specific Igm antibodies to IBV by an antibody capture ELISA. Avian Pathol 27: 2 155-160.

Dhinakar, RAJ G. and Jones, RC. (1997): Infectious bronchitis virus: immunopathogenesis of infection in the chicken. Avian Path. J. Of the W.V.P.A .26: 677-706.

Gelb, JJ.; Weisman, Y.; Ladman, BS. and Meir, R. (2005): S1 gene characteristics and efficacy of vaccination against IBV field isolates from the USA and Israel (1996-2000). Avian Pathol. 34: 194-203.

Ignjatovic, J. and Galli, L. (1995): Immune responses to structural proteins of avian infectious bronchitis virus. Avian Pathol. 24: 313-332.

Ignjatovic, J.; Gould, G. and Sapats, S. (2006): Isolation of a variant IBV in Australia that further illustrates diversity among emerging strains. Arch Virol.151: 1567-1585.

Jackwood, MW. and De Wit, JJ. (2013): IBV. In: Dis. of Poult. $13^{\text {th }}$ edition. Edit. David E. Swayne pp $139-160$.
Karaca, K. and Naqi, SN. (1993): A monoclonal antibody-based ELISA to detect serotypespecific IBV antibodies. Vet Microbiol 34: 249-257.

King, DJ. and Hopkins, SR. (1984): Rapid serotyping of IBV isolates with the HI. Avian Dis. 44: 325-335.

Kurian, A.; Neumann, EJ.; Hall, WF. and Marks, D. (2012): Effects of blood sample mishandling on ELISA results for infectious bronchitis virus, avian encephalomyelitis virus and chicken anaemia virus. The Vet. Journal 192: 378-381.

Lee, CW.; Brown, C.; Hilt, DA. and Jackwood, MW. (2004): Nephropathogenesis of chickens experimentally infected with various strains of IBV. J. Vet. Med. Sci. 66: 835-840.

Lee, EK.; Jeon, WJ.; Lee, YJ.; Jeong, OM.; Choi, JG.; Kwon, JH. and Choi, KS. (2008): Genetic diversity of avian infectious bronchitis virus isolates in Korea between 2003 and 2006. Avian Dis. 52: 332-337.

Lin, KY.; Wang, HC. and Wang, CH. (2005): Protective effect of vaccination in chicks with IBV against field virus challenge. J. Microbiol Immunol Infect. 38: 25-30.

Macnaughton, M R.; Hasony, HJ.; Madge, MH. and Reed, SE. (1981): Antibody to virus components in volunteers experimentally infected with human coronavirus 229E group viruses. Infect. \& Immun 31: 845-849.

Marquardt, WW.; Snyder, DB. and Schlotthober, BA. (1981): Detection and quantification of antibodies to IBV by ELISA. Avian Dis 25: 713-722.

Mockett, APA. and Darbyshire, JH. (1981): Comparative studies with an ELISA for antibodies to avian IBV. Avian Pathol 10: $1-10$.

Ruano, M.; El-Attrache, J. and Villegas, P. (2000): A rapid-plate HA assay for the detection of IBV. Avian Dis 44: 99-104.

Seo, SH.; Wang, L.; Smith, R. and Collisson, EW. (1997): The carboxyl terminal 120-residue polypeptide of IBV nucleo capsid induces cytotoxic T lymphocytes and protects chickens from acute infection. J. Virol. 71: 7889-7894.

Shultze, B.; Cavanagh, D. and Herrler, G. (1992): Neuraminidase treatrnent of avianIBV reveals a HA activity that is dependent on sialic acidcontaining receptors on erythrocyte. Virology 189: 792-794.

Snedecor, GW. and Cochran, WG. (1967): Statistical methods, 6th ed., Iowa State. Univ press, Ames., Iowa, USA.

Spaan, W.; Cavanagh, D. and Horzinek, MC. (1988): Coronaviruses: structure and genome expression J Gen Virol. 69: 2939-2952. 
Villegas, PC. (1991): Lab. manual .avian virus diseases. pp 19 -20.Coll. Vet. Med. Athens, Georgia.

Villegas, PC. (2006): Lab. manual .avian virus diseases. pp 33, 37-38. Coll. Vet. Med. Athens, Georgia.
Worthington, KJ.; Currie, RJW. and Jones, RCs. (2008): A RT-PCR reaction survey of IBV genotype in Western Europe from 2002 to 2006. Avian path. 37: 247-257.

\section{المقارنة بين اختبار منع التلازن الدموي واختبار الاليزا في الكثف عن الاستجابة المناعية بعد التحصين ضد فيروس

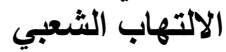

\section{هام احمد عبد البليع محدد ، محد عبل الله غنيمي هيكل}

Email: heshambayoumie@yahoo.com

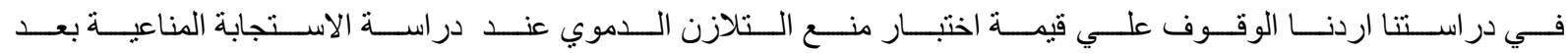

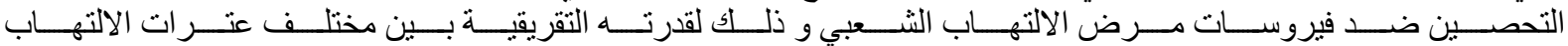

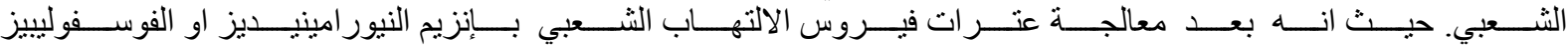

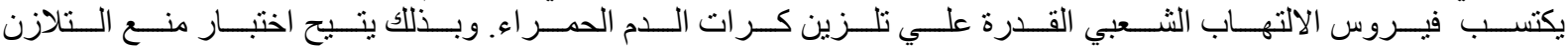

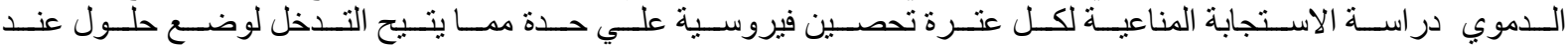

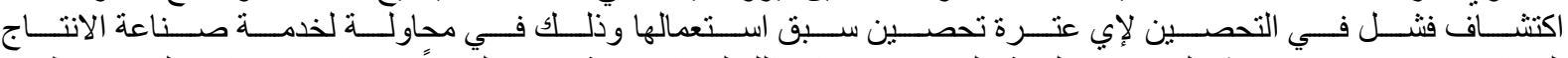

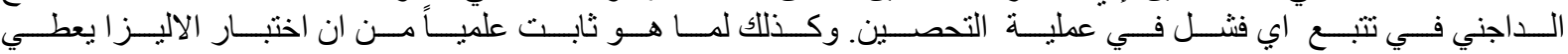

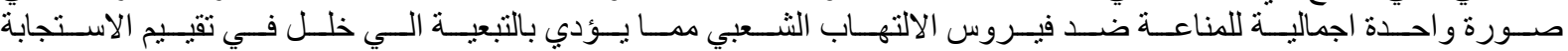

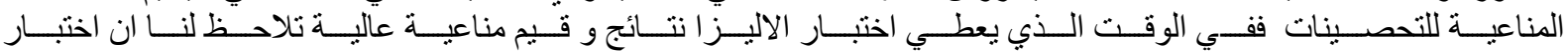

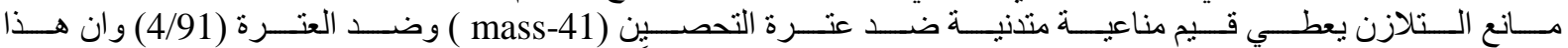

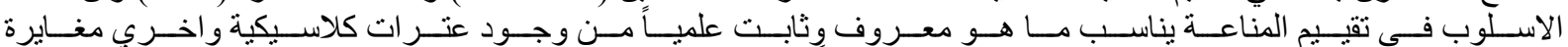

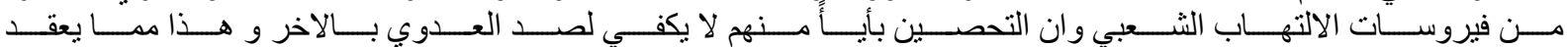

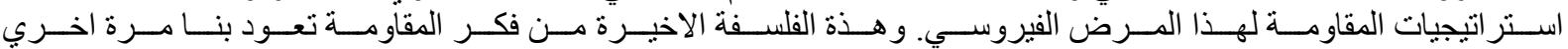

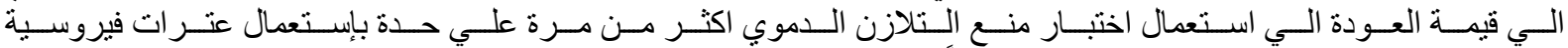

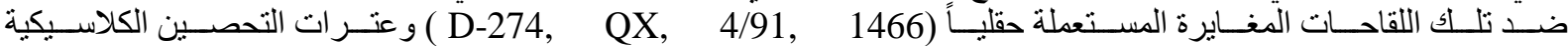

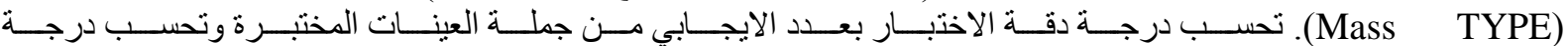

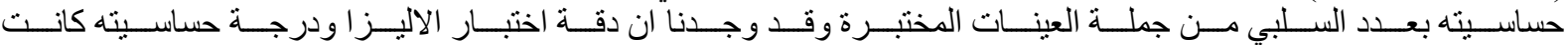

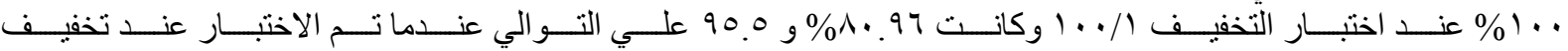

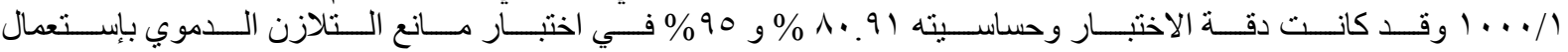

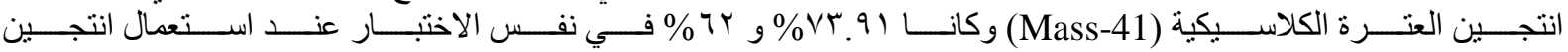

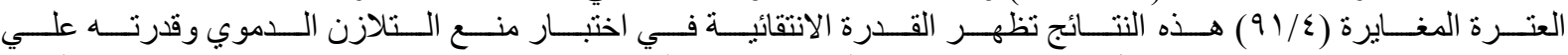

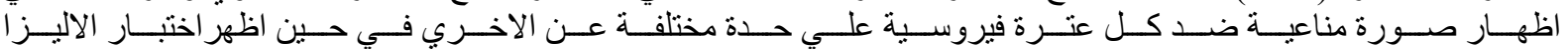

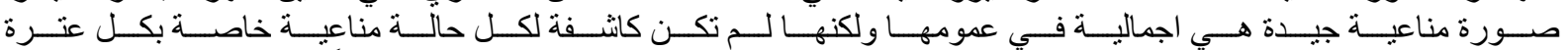

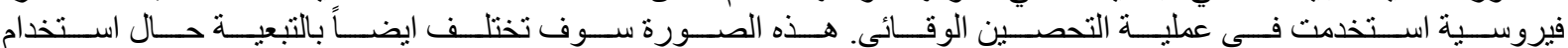

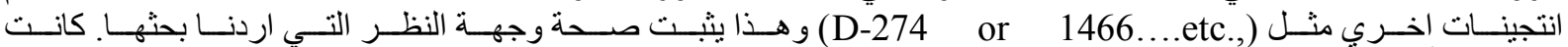

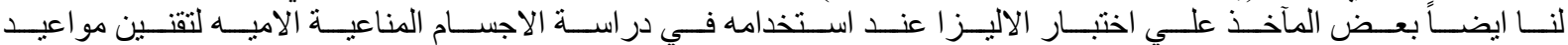

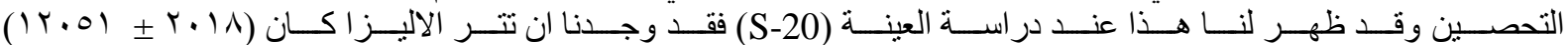

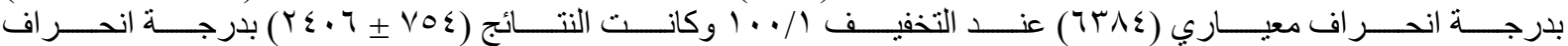

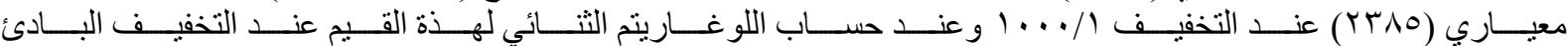

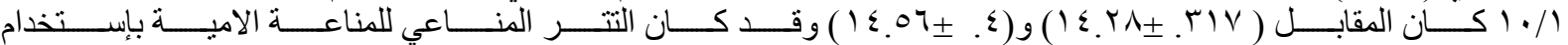

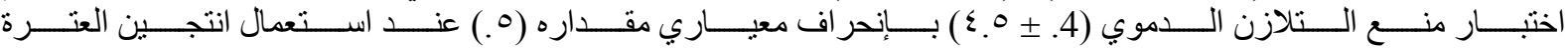

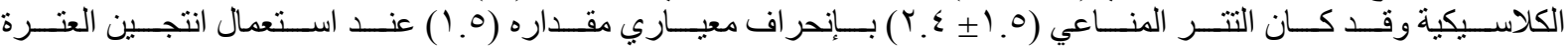
المغايرة (\$/919) وبذلك نري ان اختبار الاليزا قد يؤدي الي خطأ في تحديد مواعيد التحصين. 